\title{
España y Europa: cuando la solución es el problema
}

\section{Spain and Europe: when the Solution is the Problem}

\author{
Antonio García Santesmases \\ Universidad Nacional de Educación a Distancia \\ asantesmases@gmail.com
}

\section{Resumen}

El problema de la crisis desatada por los efectos de la Europa del Euro en España no se puede analizar sin tener en cuenta que confluyen dos problemas diferentes que hay que resolver. El uno remite a un problema específicamente español que tiene que ver con la transición a la democracia, con el modelo de la Constitución del 78 y con todos los avatares vividos en los últimos años en torno al laicismo, el republicanismo y el federalismo. El segundo remite a nuestro encaje en el modelo europeo y a la propia pervivencia del proyecto europeo.

Palabras clave: historia nacional, crisis, sindicalismo, internacionalismo, Europa social.

\begin{abstract}
The problem of the crisis triggered by the effects of the Euro's Europe in Spain cannot be analyzed without taking into account two different problems to be solved. One refers to a specifically Spanish problem which has to do with the transition to democracy, with the model of the Constitution of 1978 and all the ups and downs experienced in recent years around secularism, republicanism and federalism. The second refers to our fitting into the European model and the very survival of the European project.

Keywords: national history, crisis, trade-unionism, internationalism, social Europe.
\end{abstract}

\section{El significado de un ciclo que termina}

¿Qué ha significado el ciclo que ahora termina en relación a estos dos problemas? El ciclo que ahora termina se funda en considerar caduco el modelo constitucional del 78; creo que este ciclo inició su final con la derrota del partido socialista en las 
elecciones de noviembre del 2011. Acababa así las peripecias del gobierno de José Luis Rodríguez Zapatero, cuya gestión cabe dividir en dos etapas: la que abarca la primera legislatura y la que se desarrolla en la segunda, especialmente tras lo ocurrido el 10 de mayo del 2010 cuando se produce un giro en la política económica del gobierno y se genera un desencuentro con los sindicatos que provocará una huelga general el 29 de septiembre del 2010 y una movilización en contra de la reforma de la constitución en septiembre del 2011.

La primera legislatura había comenzado con un gesto sorprendente como fue la retirada de las tropas de Irak. Acostumbrados a la distinción de los años ochenta entre las promesas efectuadas en la oposición y los designios inexorables de la realidad, cuando se accede a los gobiernos, muchos pensaban que Zapatero haría como Felipe González, olvidaría las razones del corazón, bajaría la cabeza y aceptaría contribuir a la causa del Occidente imperial, asumiendo su cuota-parte de responsabilidad (por decirlo en el lenguaje del gobierno de aquellos años). No lo hizo y fue a partir de entonces cuando cayeron sobre él toda suerte de improperios, de vejaciones, de insultos y descalificaciones; toda la prensa de derechas le recordaba una y otra vez que, ante tal desacato a la autoridad imperial, nunca sería recibido por el Presidente Bush. Y en ese punto hay que decir que acertaron. A Bush todo aquello le pareció una afrenta intolerable y nunca le recibió mientras que a los electores de izquierda les congració con una política que respondía a sus demandas pacifistas y le volvieron a votar en el 2008.

Cuanto más bramaban los propagandistas de derechas acusándole de relativismo moral, de estar acomplejado ante el Islam, de propagar la entelequia de la Alianza de Civilizaciones, más iba siendo admirado por una parte de la opinión pública española que se sentía orgullosa de aquel gesto de independencia. Esa política, que había reconciliado al gobierno con las bases progresistas de la izquierda, fue acusada de antinorteamericana y de antioccidental; este reproche conectó con un intento de deslegitimación política de Zapatero producido desde el mismo día en que se produjo la victoria electoral de marzo del 2004. Estábamos ante un Presidente "ilegítimo", un Presidente "por accidente", un Presidente "traidor", que ponía en peligro nuestro lugar en la escena internacional y que estaba dispuesto a romper con los pactos de la transición.

A partir de ese momento comenzó el ensalzamiento de los dirigentes socialistas de los años ochenta y la demonización de los miembros de la generación zapaterista. Aquellos habían sido hombres de Estado, serios y responsables, éstos eran una generación de aventureros, insolventes e incapaces que querían abrir las heridas cerradas por la transición, fomentar un anticlericalismo trasnochado y poner en cuestión el modelo de Estado.

Hoy, pasados los meses de todo aquello y cuando llevamos más de un año de gobierno del Partido Popular, hay que decir que muchas de estas invectivas de la derecha mediática hicieron mella en muchos electores y militantes del PSOE que en estos momentos no saben a qué atenerse, no saben si tenían razón los prudentes di- 
rigentes socialistas de los años ochenta o si la razón les asiste a los que se atrevieron a dar una respuesta innovadora, por tibia que parezca a los sectores de la izquierda más radical, a los problemas de la llamada memoria histórica y a la articulación territorial del poder. Esos mismos dirigentes, caracterizados como "insolventes", que tuvieron además la audacia de apostar por la aprobación de determinados derechos cívicos como la legalización del matrimonio homosexual.

La resistencia feroz de los sectores eclesiásticos a las reformas del gobierno Zapatero, las campañas en contra de la memoria republicana que llega hasta el desatino del Diccionario aprobado por la Academia de la Historia y la sentencia del Tribunal Constitucional de julio del 2010 sobre el Estatuto de Cataluña reflejan que se habían tocado puntos extraordinariamente sensibles para los sectores conservadores.

Desde entonces son muchos los sectores mediáticos que presionan para que se vuelva a la "normalidad" y se alcance un pacto de Estado entre los partidos mayoritarios donde no se vuelvan a plantear estos temas, es decir donde se haga frente a cualquier discusión sobre la forma de Estado, sobre la unidad nacional o sobre la inserción en Europa. Los partidos mayoritarios deben salvaguardar la Europa del Euro, frente a los nacionalismos secesionistas y frente a cualquier cuestionamiento de la única política económica posible.

\section{EI nuevo escenario}

¿Es posible reeditar ese consenso a la vista de la actual crisis europea? El gobierno de Zapatero trató de reorientar la política internacional española seguida en los años de Aznar. Para ello era imprescindible fortalecer el papel de Europa en la escena internacional. Fueron los años (que hoy nos parecen lejanos a la luz de la crisis del Euro) de la reivindicación del eje franco-alemán, de la apuesta por la vieja Europa, frente a la nueva Europa dispuesta a alinearse incondicionalmente con los Estados Unidos. Fueron los años en los que Colin Powel se quedaba en minoría en el Consejo de Seguridad de Naciones Unidas. Volver a Europa era la consigna que animaba a muchos electores españoles que habían abominado de la guerra de Irak y habían llenado las calles españolas en contra del trío de las Azores.

La retirada de las tropas de Irak, la apuesta por un ministro como Moratinos (resistiendo las presiones a favor del nombramiento de Javier Solana como Ministro de Exteriores) se enmarcaron en un proyecto donde España quería ser la primera en suscribir la Constitución europea, y estaba dispuesta a encabezar entusiasta el "gran paso adelante". Un paso que una parte de la opinión pública entendía imprescindible para afianzar una Europa líder frente a los Estados Unidos de Bush y dispuesta a implicarse en los problemas del Mediterráneo, el conflicto de Oriente Medio y en la incorporación de Turquía a la Unión europea.

Programa tan ambicioso hizo que en España no se discutiera apenas acerca de las bondades y las limitaciones del proyecto de Constitución Europea. De ahí la sorpresa 
ante el No en el referéndum en Francia. Nada parecido a los debates entre Gunter Grass y O. Lafontaine o entre J. Habermas y P. Anderson se produjo en España. Y no fue porque en España no apasionen los debates internacionales. Creo que la razón es más profunda y remite a la historia de España en el siglo veinte.

Si recordamos lo ocurrido en los años ochenta del siglo pasado podemos ver la diferencia. El debate sobre la permanencia de España en la OTAN provocó la intervención de los intelectuales más importantes de aquel momento como Jose Luis Aranguren, Manuel Sacristán o Rafael Sánchez Ferlosio y la irrupción de movimientos sociales (Comisión anti-OTAN) que conectaban con los debates que protagonizaban en Europa los movimientos pacifistas, favorables a la distensión y al desarme nuclear. Todo aquel clima cuajó en España porque existía el recuerdo del apoyo inequívoco de Estados Unidos a la Dictadura de Franco. No era posible vender las bondades democráticas de una Alianza militar que había apoyado una dictadura.

A diferencia de la OTAN, la Comunidad Económica Europea sí aparecía como el marco imprescindible para alcanzar una democracia plena, como la meta deseable a la que no pudimos acceder, tras el final de la segunda guerra mundial, por los imperativos de la guerra fría; por fin había llegado el momento y España podía estar en su sitio. En un lugar en el mundo que había conseguido superar la crisis de los años treinta y alcanzar los años dorados del Estado del Bienestar. Mientras los europeos conjugaban prosperidad económica con pleno empleo, consolidaban los derechos económico-sociales y fomentaban la redistribución de la riqueza, nosotros tuvimos que soportar la dictadura, nuestros trabajadores emigraban, los sindicatos y los partidos estaban prohibidos y el falso consumismo tapaba la realidad de un Estado dictatorial.

Queríamos salir de ese pasado tenebroso y homologarnos como fuera con Europa e incorporarnos cuanto antes: de ahí la razón de la unanimidad en torno al proyecto europeo frente a la confrontación que provocó el ingreso en la OTAN. Esa homologación a cualquier precio provoca que sean muchos los que se pregunten ¿hemos hecho en España un debate sobre lo que implica el actual proyecto europeo?

Creo que no. Las consecuencias más relevantes del actual pacto del Euro como son la limitación radical de la soberanía de los países miembros y la imposición de una única política económica que vacía de contenido la práctica de la democracia, no se han discutido en nuestro país hasta fecha muy reciente. No habían aparecido ni por asomo en las posiciones de la derecha política que sólo trataba de endosar la responsabilidad de la crisis a las decisiones del gobierno de Zapatero. Querían convencer a la opinión pública de que todo se debía a la maldad del hombre que nunca debió llegar a gobernar, que todo cambiaría cuando volviera la confianza a los mercados. Y de ahí que todas las reformas emprendidas en estos meses, reformas que han provocado dos huelgas generales en el 2012 e infinidad de conflictos sociales, sean siempre justificadas por la herencia recibida pero también -y de ahí la necesi- 
dad de abrir un debate sobre la Europa del Euro- por los imperativos emanados de Bruselas y de Berlín.

El problema es que desde hace mucho tiempo de Europa no vienen más que malas noticias y por ello seguir repitiendo el estribillo de que lo que necesitamos es más Europa no suscita el menor entusiasmo en la población afectada por los recortes o temerosa del futuro. Por ello lo que hace meses parecía impensable ha ocurrido. La pregunta que cada vez se hace más gente no es si necesitamos más Europa sino qué Europa queremos: ¿La Europa que impone reformas de la constitución que atentan contra los derechos económico-sociales, contra la supervivencia del Estado del bienestar, contra el modelo social del que hasta hace poco se vanagloriaba?

\section{Tres escenarios posibles}

Ante esta situación se dibujan tres escenarios posibles: en el primero se trata de mantener las cosas como están, de asegurar que sólo cabe una política económica que deben desarrollar los partidos de gobierno, sean de derechas o de izquierdas. La segunda posibilidad es que se produzca una inflexión en las políticas europeas por la presencia de un nuevo actor capaz de cambiar los parámetros del debate: por ahí van los intentos de los sindicatos europeos plasmados en la huelga del pasado 14 de noviembre del 2012 y, en tercer lugar, que crezca cada vez más el deseo de abandonar el euro.

La primera posición es la que tiene mayor fuerza dentro de las elites políticas, económicas y mediáticas. A lo largo del año 2012 hemos vivido dos huelgas generales, una marcha impresionante de los mineros desde Asturias hasta Madrid, una serie de movilizaciones muy relevantes en el campo de la educación y de la sanidad y una gran lucha social contra la política de las instituciones financieras en el tema de los desahucios. Todas estas batallas han conmovido a la opinión pública por la identificación con las causas que movilizaban a los manifestantes: por la necesidad de combatir la precariedad en el empleo, el paro estructural, la privatización de la sanidad, la subida de las tasas académicas y el carácter abusivo de los intereses financieros.

El clima de apoyo a las movilizaciones ha ido unido a un clima de progresivo encrespamiento por haber percibido que los recortes en todos estos derechos económico-sociales ha ido unido al descubrimiento de casos de corrupción que afectan a la familia real, a los grandes partidos políticos, a las instituciones financieras y a los grandes medios de comunicación.

Ante este clima de recorte de derechos y de corrupción institucionalizada, se ha perdido la autoridad moral para pedir sacrificios a la población. Esa pérdida de legitimidad se intenta compensar una y otra vez con la tesis de lo que se hace es inevitable, que viene impuesto por nuestra condición de miembros de la zona Euro y que cualquier otra alternativa sería peor. Si no aceptamos lo que nos exigen no 
financiarían nuestros gastos y acabaríamos siendo intervenidos. Si queremos seguir en Europa no tenemos más remedio que apechugar con las consecuencias.

Ante esta situación han ido apareciendo reacciones que reclaman estrategias de muy distinto tipo. La primera reacción plantea que no hay que discutir la permanencia en el Euro ni poner en cuestión los compromisos que exigen Bruselas o Berlín. Lo que sí hay que poner en cuestión es la permanencia dentro del Estado Español. La posición del nacionalismo catalán en este punto es clara: Euro sí; España no. Se trata de ser un nuevo Estado en Europa que abandone a España a su suerte.

La fuerza del nacionalismo catalán tras la Diada del 11 de septiembre del 2012 y tras el ascenso de Ezquerra Republicana en las elecciones del 25 de noviembre plantea un problema de desafío a la unidad nacional española que se sustenta en ocasiones en consideraciones parecidas a las que difunden los políticos alemanes sobre la Europa del Sur. La vuelta de viejos prejuicios acerca del carácter emprendedor, laborioso y ahorrador, de los alemanes frente al carácter indolente y pasivo, dado a la vagancia y a la ociosidad, de las poblaciones del Sur aparece en muchos políticos nacionalistas catalanes que reclaman la secesión para poder ser catalanes y europeos.

Cuando los sindicatos plantearon en la huelga del pasado 14 de noviembre del 2012 una nueva estrategia intentaban dos cosas: por un lado ampliar su base social abriéndose a los movimientos sociales que estaban cuestionando la política de recortes y buscando nuevas alternativas a la actual crisis, pero intentaban también que la protesta no fuera solo nacional que fuera europea. Para ello intentaban lo más difícil y lo más necesario, intentaban que la protesta trascendiera las fronteras nacionales. Intentaban que los trabajadores y los ciudadanos alemanes y holandeses se sintieran griegos y portugueses, españoles e italianos. Sólo logrando que el trabajador alemán viva como propias las reivindicaciones de los trabajadores o de los parados griegos o portugueses, españoles o italianos es posible que los sindicatos europeos puedan constituirse en un nuevo sujeto político con el que inexorablemente haya que negociar, que pactar, y que acordar. Sin esa fuerza internacional de lo que queda del movimiento obrero la batalla está perdida.

Lo está porque la tercera posibilidad también es nacional. La primera opción es seguir como estamos y asegurar que gobierne la derecha o la izquierda sólo cabe una política impuesta por Bruselas. La segunda opción es que los sindicatos logren una rectificación que permita detener el camino que estamos siguiendo y volver a la senda de la Europa social. Son muchos los que consideran que ese sindicalismo operativo, potente, eficaz es una quimera y que, por tanto, es preferible prepararse para el estallido del Euro y adelantar la salida de la moneda única. Esta posición hasta ahora es muy minoritaria porque- y no hay más remedio que volver a la historia de España- para muchas generaciones de españoles Europa siempre ha sido la solución. Abandonar la moneda es como abandonar la casa a la que se quería haber llegado, reconocer que todo el sueño se ha convertido en una pesadilla. Máxime cuando esa pesadilla va unida al problema de quién se va del Euro. 
Pensemos para terminar en la gran paradoja. Encima de la mesa tenemos las dos propuestas: unos se quieren ir de España pero no del euro, otros no cuestionan la unidad nacional pero sí la permanencia en el euro y reclaman un nuevo proceso constituyente, a escala española y europea. Un nuevo proceso constituyente para instaurar una tercera república en España. Ante esta situación sólo cabe recordar que la historia europea ha marcado la vida española: la marcó en el apoyo de la Alemania Nazi y la Italia Fascista a la sublevación militar; la marcó en la política de no intervención de Francia e Inglaterra en la guerra civil; la marcó en la política norteamericana de apoyo a la dictadura de Franco y la marcó en la incorporación a la comunidad económica europea.

Nos incorporamos cuando también lo hicieron Grecia y Portugal. También ellos habían vivido dictaduras y también ellos vivieron la esperanza de una Europa que los acogía. Hoy ya no se sienten miembros de esa comunidad, de ella no vienen más que malas noticias, sus naciones se ven cuestionadas y no acaban de ver salida.

Yo apuesto por un nuevo internacionalismo que logre rectificar el curso de las cosas, creo que a eso debemos dedicar las energías pero contemplo que tanto los que piden la secesión como los que reclaman un nuevo proceso constituyente van creciendo. Un nuevo Estado en Europa o una nueva república aparecen como alternativas mucho más atractivas. Se puede argumentar que un nuevo Estado que asuma la actual arquitectura europea no cambia las cosas, se puede argumentar igualmente que tanto Portugal como Grecia son repúblicas y están sufriendo las consecuencias inexorables de la crisis. Las dos cosas son verdad pero para muchos son tablas a las que agarrarse, identidades en las que refugiarse ante la uniformización económica. Los que reclamamos otra Europa, una Europa social, para atender las reivindicaciones de los sindicatos y de los movimientos sociales vamos quedando en minoría. El sindicalismo y el internacionalismo no son banderas que hoy susciten entusiasmo, pero sin enarbolar esas banderas y sin atender a esas reivindicaciones otra Europa no es posible y nuestros problemas seguirán sin encontrar solución. 